\title{
Mitochondrial Protection and Anti-aging Activity of Astragalus Polysaccharides and Their Potential Mechanism
}

\author{
Xing-Tai Li ${ }^{1}{ }^{*}$, Ya-Kui Zhang ${ }^{2}$, Hai-Xue Kuang ${ }^{3}$, Feng-Xin Jin ${ }^{2}$, De-Wen Liu ${ }^{2}$, \\ Ming-Bo Gao ${ }^{1}$, Ze Liu ${ }^{1}$ and Xiao-Juan Xin ${ }^{2}$
}

1 College of Life Science, Dalian Nationalities University, No.18 Liaohe West Road, Dalian Economic \& Technical Development Zone, Dalian 116600, China;

E-Mails: lily@dlnu.edu.cn (M.-B.G.); liuze@dlnu.edu.cn (Z.L.)

2 Daxing'anling Academy of Agriculture and Forestry Sciences, Jiagedaqi 165000, China;

E-Mails: zhangyk02@yahoo.com.cn (Y.-K.Z.); lksjfx@126.com (F.-X.J.);

ldwen817@yahoo.com.cn (D.-W.L.); xinxiaojuan323@163.com (X.-J.X.)

3 College of Pharmacy, Heilongjiang University of Traditional Chinese Medicine, Harbin 150040, China; E-Mail: hxkuang@hotmail.com

* Author to whom correspondence should be addressed; E-Mail: xtli@ dlnu.edu.cn;

Tel.: +86-411-87630445; Fax: +86-411-87644496.

Received: 31 December 2011; in revised form: 21 January 2012 / Accepted: 29 January 2012 / Published: 7 February 2012

\begin{abstract}
The current study was performed to investigate mitochondrial protection and anti-aging activity of Astragalus polysaccharides (APS) and the potential underlying mechanism. Lipid peroxidation of liver and brain mitochondria was induced by $\mathrm{Fe}^{2+}-\mathrm{Vit} \mathrm{C}$ in vitro. Thiobarbituric acid (TBA) colorimetry was used to measure the content of thiobarbituric acid reactive substances (TBARS). Mouse liver mitochondrial permeability transition (PT) was induced by calcium overload in vitro and spectrophotometry was used to measure it. The scavenging activities of APS on superoxide anion $\left(\mathrm{O}_{2}{ }^{-}\right)$and hydroxyl radical $(\cdot \mathrm{OH})$, which were produced by reduced nicotinamide adenine dinucleotide (NADH) - N-Methylphenazonium methyl sulfate (PMS) and hydrogen peroxide $\left(\mathrm{H}_{2} \mathrm{O}_{2}\right)-\mathrm{Fe}^{2+}$ system respectively, were measured by 4-nitrobluetetrazolium chloride (NBT) reduction and Fenton reaction colorimetry respectively. The $\mathrm{Na}_{2} \mathrm{~S}_{2} \mathrm{O}_{3}$ titration method was used to measure the scavenging activities of APS on $\mathrm{H}_{2} \mathrm{O}_{2}$. APS could inhibit TBARS production, protect mitochondria from $\mathrm{PT}$, and scavenge $\mathrm{O}_{2}{ }^{-}, \cdot \mathrm{OH}$ and $\mathrm{H}_{2} \mathrm{O}_{2}$ significantly in a concentration-dependent manner respectively. The back of the neck of mice was injected subcutaneously with D-galactose to induce aging at a dose of $100 \mathrm{mg} / \mathrm{kg} / \mathrm{d}$ for
\end{abstract}


seven weeks. Moreover, the activities of catalase (CAT), surperoxide dismutase (SOD) and glutathione peroxidase (GPx) and anti-hydroxyl radical which were assayed by using commercial monitoring kits were increased significantly in vivo by APS. According to this research, APS protects mitochondria by scavenging reactive oxygen species (ROS), inhibiting mitochondrial PT and increasing the activities of antioxidases. Therefore, APS has the effect of promoting health.

Keywords: Astragalus polysaccharides; mitochondria; anti-aging; antioxidant; reactive oxygen species; mitochondrial permeability transition

\section{Introduction}

The free radical theory of aging is based on the works of Gerschman and Harman, and when focused in mitochondria emerged as the mitochondrial hypothesis of aging [1,2]. It holds that during aging, an increase in reactive oxygen species (ROS) in mitochondria causes mutations in the mtDNA and damages mitochondrial components, resulting in senescence [3]. Mitochondria are considered the pacemakers of tissue aging due to the continuous production of free radicals, oxygen, and nitrogen free radicals and related reactive species, and to the selective oxidative damage that leads to mitochondrial dysfunction [4]. Mitochondria are the driving force behind life, as mitochondrial oxidative phosphorylation provides the main source of energy in the cell. In addition to energy production, mitochondria play a crucial role in mediating amino acid biosynthesis, fatty acid oxidation, steroid metabolism, intermediate metabolic pathways, calcium homeostasis, and free radical scavenging [5]. Mitochondria are a major source of ROS, which are a byproduct of mitochondrial electron transfer activity. Molecular oxygen $\left(\mathrm{O}_{2}\right)$ is highly electrophilic and superoxide production occurs when $\mathrm{O}_{2}$ captures an electron from Complex I or from the ubisemiquinone located in Complex III. Normally, superoxide is detoxified by the combined activity of the mitochondrial antioxidant enzymes manganese surperoxide dismutase (MnSOD), catalase (CAT) and glutathione peroxidase (GPx) [6]. Superoxide anion $\left(\mathrm{O}_{2}{ }^{--}\right)$is the precursor of most ROS and is a mediator in oxidative chain reactions. Dismutation of $\mathrm{O}_{2}{ }^{--}$, either spontaneously or through a catalytic reaction by surperoxide dismutase (SOD), produces hydrogen peroxide $\left(\mathrm{H}_{2} \mathrm{O}_{2}\right)$, which in turn may be fully reduced to water by CAT and GPx or partially reduced to a hydroxyl radical $(\bullet \mathrm{OH})$, one of the strongest oxidants in nature [7]. $\bullet \mathrm{OH}$ may be re-reduced by $\mathrm{O}_{2}{ }^{--}$and may propagate the entire ROS process [8]. As a consequence of their biological functions, mitochondria are always exposed to ROS production and have a complex antioxidant defense system to counteract it. Oxidative stress occurs when the homeostatic balance between oxidant and antioxidant capacities in a determined biological system is disturbed [9]. Thus, under conditions of oxidative stress, mitochondria may suffer from oxidative damage to their biomolecules. Since the removal and repair of altered structures may not be completely efficient, the oxidizing products might accumulate in this organelle.

Astragali Radix is derived from the dried roots of Astragalus membranaceus (Fisch.) Bunge or A. membranaceus (Fisch.) Bunge var. mongholicus (Bunge) Hsiao (AM, Huang-qi in Chinese), is one of the most frequently used Qi-invigorating herbal medicines in traditional Chinese medicine for 
millennia. AM is often used in formulas for deficiency of Qi (vital energy) characterized by limb weakness, fatigue, lack of appetite, and dizziness. It is considered that AM is the most popular for Qi-tonifying herbal medicines and is often used as an antiperspirant, an immunostimulant, a diuretic, and a supplementary medicine during cancer therapy [10]. AM has various bioactivities, such as anti-aging [11], hepatoprotective, antibacterial, inducing cancer cell apoptosis [12], and preventing apoptosis in cultured neonatal cardiomyocytes [13]. AM inhibited mitochondrial oxygen consumption and malondialdehyde (MDA) production [14]. Recently, most of the constituents including triterpene saponins, isoflavonoids, and polysaccharides were isolated from AM, and their bioactive effects were also investigated $[15,16]$. As an important bioactive component of AM, Astragalus polysaccharides (APS) have immunoregulatory, antiviral, hypoglycemic, antioxidant, and antitumor properties [17-20]. Therefore, APS have received a great deal of attention [21] and have been applied in the treatment of many diseases, including tumor and infectious diseases, in Chinese medicine [22]. APS therapy ameliorated vacuolar degeneration of mitochondria and fragmentation of mitochondrial cristae of hepatocytes in insulin-resistance mice, which indicates the mitochondrial dysfunction coupled with the increased metabolic stress and the protective effect of APS [19].

However, there has been no report on how mitochondria were protected and the mechanism of protective effect on mitochondrial injury by APS so far. As the 'hubs' for cellular metabolism, mitochondria are crucial for both life and death of eukaryotic cells, and are the main switch of cell apoptosis. In the present study, the mechanism underlying mitochondrial protection and anti-aging activities of APS were investigated and evaluated by the inhibition of mitochondrial permeability transition (PT), the scavenging abilities on ROS and the effects on activities of the antioxidases.

\section{Results and Discussion}

\subsection{Lipid Peroxidation Prevented in Liver and Brain Mitochondria in Vitro}

Peroxidation of membrane lipids has been suggested to be one of the major causes of decreased mitochondrial membrane function [23]. Oxidative damage was studied by measuring lipid peroxidation (LPO) products such as thiobarbituric acid reactive substances (TBARS). The TBARS level, used as an auto-oxidation index of LPO in tissues, is used to screen the antioxidants. Pro-oxidants and ROS result in LPO in mitochondria [24]. It is widely accepted that LPO increases with age [25]. In fact, peroxidation alters the structure of membrane lipids, which can disrupt the structural organization of the lipid double layer, altering membrane fluidity and permeability. A significant increase in the peroxidation products has been reported in rat liver mitochondria [26]. Also, in mice skeletal muscle mitochondria, Faist et al. have demonstrated an increased mitochondrial formation of TBARS with age [27]. Unsaturated lipids in liver tissue are very susceptible to peroxidation when they are exposed to pro-oxidative metal ions such as $\mathrm{Fe}^{2+}$. It has long been thought that $\mathrm{Fe}^{2+}$ is the most likely active species, producing oxidants through interaction of $\mathrm{Fe}^{2+}$ with oxygen. In the current investigation we have incubated the mouse liver and brain mitochondria with or without the presence of $\mathrm{Fe}^{2+}$, and examined their effects on mitochondria by measuring the absorbance at $532 \mathrm{~nm}$. The current results show that formation of TBARS in mitochondria, which was enhanced significantly following 
treatment with $\mathrm{Fe}^{2+}$-Vitamin $\mathrm{C}$, was inhibited in a concentration-dependent manner in presence of APS (Table 1), which indicates that APS possess the antioxidant activity.

Table 1. The effects of Astragalus polysaccharides (APS) on thiobarbituric acid reactive substances (TBARS) in liver and brain mitochondria $(n=6)$. Data were expressed as means \pm S.D. and statistical differences between groups were analyzed by one-way analysis of variance (ANOVA).

\begin{tabular}{cccccc}
\hline Group & $\begin{array}{c}\text { Concentration } \\
(\mathbf{m g} / \mathbf{L})\end{array}$ & $\begin{array}{c}\text { C(liver) } \\
(\mathbf{n m o l} / \mathbf{m g} \text { protein) }\end{array}$ & $\begin{array}{c}\text { Liver } \\
\text { IR\% }\end{array}$ & $\begin{array}{c}\text { C(brain) } \\
\text { (nmol/mg protein) }\end{array}$ & $\begin{array}{c}\text { Brain } \\
\text { IR\% }\end{array}$ \\
\hline Normal & - & $0.62 \pm 0.38^{\mathrm{b}}$ & & $0.38 \pm 0.29^{\mathrm{b}}$ & \\
Model & - & $4.32 \pm 1.65$ & & $4.84 \pm 1.62$ & \\
APS & 2.0 & $3.56 \pm 0.89$ & 20.54 & $4.05 \pm 1.16$ & 17.71 \\
& 4.0 & $3.08 \pm 0.53$ & 33.51 & $3.46 \pm 0.78$ & 30.94 \\
& 8.0 & $2.37 \pm 0.65^{\mathrm{a}}$ & 52.70 & $2.88 \pm 0.66^{\mathrm{a}}$ & 43.95 \\
& 16.0 & $1.65 \pm 0.49^{\mathrm{b}}$ & 72.16 & $1.96 \pm 0.57^{\mathrm{b}}$ & 64.57 \\
& 32.0 & $0.92 \pm 0.35^{\mathrm{b}}$ & 91.89 & $1.35 \pm 0.79^{\mathrm{b}}$ & 78.25 \\
\hline
\end{tabular}

${ }^{\mathrm{a}} P<0.05,{ }^{\mathrm{b}} P<0.01$, compared with model group. C: TBARS contents; IR: inhibition rate; APS: Astragalus polysaccharides.

\subsection{Inhibition of Liver Mitochondrial Permeability Transition}

Permeability and fluidity of mitochondrial membrane are prerequisites for maintaining mitochondrial functions; the status of the mitochondrial membrane potential, which is an estimate of the electrochemical gradient across the inner mitochondrial membrane, and thus the mitochondrial permeability transition pore (MPTP) opening. ROS can stimulate the opening of MPTP [28]. Mitochondrial PT is a sensitive index for surveying permeability of the membrane and assessing mitochondrial functions. High levels of pro-oxidants produced by mitochondria can induce apoptosis by changing cellular redox status, depleting reduced glutathione (GSH) [29]. Pro-oxidants and ROS result in opening of MPTP in mitochondria [24]. Onset of the permeability transition was monitored from the changes of absorbance at $540 \mathrm{~nm}$, which reflect mitochondrial permeabilization to sucrose. Mitochondria were challenged with a $\mathrm{Ca}^{2+}$ load of $150 \mu \mathrm{M}$, which caused a detectable permeability transition. After $\mathrm{Ca}^{2+}$ accumulation ruthenium red (RR) was added to prevent $\mathrm{Ca}^{2+}$ redistribution [30], rapid and large amplitude mitochondrial swelling was induced by $\mathrm{Ca}^{2+}$, indicating that the swelling was because of the opening of the MPTP, and the effects of $\mathrm{Ca}^{2+}$ were blocked completely by $0.5 \mu \mathrm{M}$ $\mathrm{RR}$ and partially blocked by $0.3 \mu \mathrm{M} R \mathrm{R}$ in this study. LPO can lead to increase of membrane permeability thus, mitochondrial swelling is initiated. APS inhibited $\mathrm{Ca}^{2+}$ induced mitochondrial PT significantly and the inhibitory potency was stronger when the incubation time was longer and concentration of APS was higher. No significant difference was observed between APS $(64 \mathrm{mg} / \mathrm{L})$ and the normal (Table 2). The inhibition of mitochondrial PT by APS was closely related to its scavenging activity on ROS and the inhibition on LPO, which indicates that maybe APS protect mitochondria by scavenging ROS and antioxidation. 
Table 2. The effect of APS on liver mitochondrial permeability transition induced by $\mathrm{Ca}^{2+}$ $(n=6)$. Data were expressed as means \pm S.D. and statistical differences between groups were analyzed by one-way analysis of variance (ANOVA).

\begin{tabular}{|c|c|c|c|c|c|c|}
\hline \multicolumn{7}{|c|}{$A_{540 \mathrm{~nm}}$} \\
\hline Group & Normal & Model & $\mathbf{R R}(0.3 \mu \mathrm{M})$ & $\mathrm{RR}(0.5 \mu \mathrm{M})$ & $\begin{array}{c}\text { APS } \\
(32 \mathrm{mg} / \mathrm{L})\end{array}$ & $\begin{array}{c}\text { APS } \\
(64 \mathrm{mg} / \mathrm{L})\end{array}$ \\
\hline 0 min & $0.481 \pm 0.035$ & $0.493 \pm 0.033$ & $0.486 \pm 0.024$ & $0.479 \pm 0.038$ & $0.480 \pm 0.034$ & $0.491 \pm 0.026$ \\
\hline $2 \min$ & $0.452 \pm 0.031^{\mathrm{a}}$ & $0.405 \pm 0.023$ & $0.429 \pm 0.028$ & $0.448 \pm 0.029^{\mathrm{a}}$ & $0.422 \pm 0.024$ & $0.443 \pm 0.022^{a}$ \\
\hline $5 \mathrm{~min}$ & $0.431 \pm 0.033^{b}$ & $0.366 \pm 0.026$ & $0.402 \pm 0.023^{\mathrm{a}}$ & $0.432 \pm 0.025^{b}$ & $0.394 \pm 0.018$ & $0.419 \pm 0.023^{b}$ \\
\hline $10 \mathrm{~min}$ & $0.413 \pm 0.030^{b}$ & $0.341 \pm 0.033$ & $0.383 \pm 0.031^{\mathrm{a}}$ & $0.415 \pm 0.037^{b}$ & $0.376 \pm 0.036$ & $0.407 \pm 0.035^{b}$ \\
\hline $15 \mathrm{~min}$ & $0.398 \pm 0.046^{b}$ & $0.309 \pm 0.034$ & $0.376 \pm 0.026^{b}$ & $0.400 \pm 0.035^{b}$ & $0.361 \pm 0.036^{\mathrm{a}}$ & $0.393 \pm 0.036^{b}$ \\
\hline $30 \mathrm{~min}$ & $0.369 \pm 0.033^{b}$ & $0.276 \pm 0.041$ & $0.355 \pm 0.038^{b}$ & $0.371 \pm 0.043^{b}$ & $0.336 \pm 0.035^{\mathrm{a}}$ & $0.366 \pm 0.045^{b}$ \\
\hline
\end{tabular}

\subsection{Scavenging Activity of APS on Superoxide Anion, Hydroxyl Radicals and Hydrogen Peroxide}

ROS are chemically reactive molecules derived from oxygen. There is increasing evidence that accumulation of ROS in biological system causes oxidative damage to tissue that affects cellular integrity and functions. Oxidative damage caused by ROS has been frequently proposed to be associated with the pathogenesis of various diseases and aging [31]. The mitochondrial electron transport chain (ETC) consumes more than $90 \%$ of the oxygen taken up by the cell, and up to $5 \%$ of that is converted into $\mathrm{O}_{2}{ }^{-}$even during a normal physiological state [32]. Superoxide anion, as the precursor of the more ROS including $\bullet \mathrm{OH}$ and $\mathrm{H}_{2} \mathrm{O}_{2}$, is very harmful to the cellular components in a biological system. The primary ROS generated in the mitochondria is $\mathrm{O}_{2}{ }^{--}$which is then converted to $\mathrm{H}_{2} \mathrm{O}_{2}$ by spontaneous dismutation or by SOD [33]. Although $\mathrm{H}_{2} \mathrm{O}_{2}$ is not very reactive, its high penetrability of cellular membrane leads to $\bullet \mathrm{OH}$ formation when it reacts with ferrous ion or $\mathrm{O}_{2}{ }^{-}$. Hydroxyl radical is very reactive and can be generated through the Fenton reaction. Superoxide anion was generated by non-enzymatic reduced nicotinamide adenine dinucleotide/N-Methylphenazonium methyl sulfate (NADH/PMS) system in the present study. The absorbance (A) value at $560 \mathrm{~nm}$ of APS group decreased significantly compared with the control group. The current studies showed that APS scavenged $\mathrm{O}_{2}{ }^{-}, \mathrm{H}_{2} \mathrm{O}_{2}$ and $\bullet \mathrm{OH}$ concentration-dependently (Table 3 and 4). The abilities of APS and the reference compound [butylated hydroxytoluene (BHT) and vitamin C] to quench the three kinds of ROS are reflected in Tables 3 and 4. Scavenging rate (SR\%) of APS $(64 \mathrm{mg} / \mathrm{L})$ for $\mathrm{O}_{2}{ }^{--}$and $\bullet \mathrm{OH}$ are $60.64 \%$ and $85.29 \%$ respectively.

Table 3. The scavenging effect of APS on $\mathrm{O}_{2} \bullet^{-}$and $\bullet \mathrm{OH}(n=6)$. Data were expressed as means \pm S.D. and statistical differences between groups were analyzed by one-way analysis of variance (ANOVA).

\begin{tabular}{cccccccc}
\hline Group & $\begin{array}{c}\text { Conc. } \\
(\mathbf{m g} / \mathrm{L})\end{array}$ & $\boldsymbol{A}_{\mathbf{5 6 0 n m}}\left(\mathbf{O}_{2^{\bullet}}{ }^{-}\right)$ & $\begin{array}{c}\text { SR\% } \\
\left(\mathbf{O}_{2}{ }^{-}\right)\end{array}$ & Group & $\begin{array}{c}\text { Conc. } \\
(\mathbf{m g} / \mathbf{L})\end{array}$ & $\boldsymbol{A}_{\mathbf{5 3 6 ~ n m}}(\bullet \mathbf{O H})$ & $\begin{array}{c}\text { SR\% } \\
(\bullet \mathbf{O H})\end{array}$ \\
\hline $\begin{array}{c}\text { Control } \\
\text { Vitamin C }\end{array}$ & - & $0.376 \pm 0.038$ & & Blank & - & $0.136 \pm 0.019^{\mathrm{b}}$ & \\
\hline
\end{tabular}


Table 3. Cont.

\begin{tabular}{|c|c|c|c|c|c|c|c|}
\hline Group & $\begin{array}{c}\text { Conc. } \\
(\mathrm{mg} / \mathrm{L})\end{array}$ & $A_{560 \mathrm{~nm}}\left(\mathrm{O}_{2^{\bullet}}{ }^{-}\right)$ & $\begin{array}{l}\text { SR\% } \\
\left(\mathrm{O}_{2^{-}}\right) \\
\end{array}$ & Group & $\begin{array}{c}\text { Conc. } \\
(\mathrm{mg} / \mathrm{L})\end{array}$ & $A_{536 \mathrm{~nm}}(\bullet \mathrm{OH})$ & $\begin{array}{l}\text { SR\% } \\
(\bullet \mathrm{OH}) \\
\end{array}$ \\
\hline \multirow{9}{*}{ APS } & 8 & $0.271 \pm 0.048^{b}$ & 27.93 & \multirow[t]{4}{*}{ BHT } & 0.30 & $0.045 \pm 0.020$ & 10.78 \\
\hline & 16 & $0.220 \pm 0.033^{b}$ & 41.49 & & 0.60 & $0.072 \pm 0.018^{b}$ & 37.25 \\
\hline & 32 & $0.117 \pm 0.026^{b}$ & 68.88 & & 1.20 & $0.101 \pm 0.028^{b}$ & 65.69 \\
\hline & 64 & $0.065 \pm 0.028^{b}$ & 82.71 & & 2.40 & $0.128 \pm 0.025^{b}$ & 92.16 \\
\hline & 4 & $0.361 \pm 0.028$ & 3.99 & \multirow[t]{5}{*}{ APS } & 4 & $0.042 \pm 0.017$ & 7.84 \\
\hline & 8 & $0.335 \pm 0.029$ & 10.90 & & 8 & $0.066 \pm 0.026^{\mathrm{a}}$ & 31.37 \\
\hline & 16 & $0.286 \pm 0.037^{b}$ & 23.94 & & 16 & $0.088 \pm 0.021^{b}$ & 52.94 \\
\hline & 32 & $0.220 \pm 0.042^{b}$ & 41.49 & & 32 & $0.107 \pm 0.013^{b}$ & 71.57 \\
\hline & 64 & $0.148 \pm 0.036^{b}$ & 60.64 & & 64 & $0.121 \pm 0.014^{b}$ & 85.29 \\
\hline
\end{tabular}

${ }^{\mathrm{a}} P<0.05,{ }^{\mathrm{b}} P<0.01$, compared with control group. Conc: Concentration; BHT: butylated hydroxytoluene; SR: Scavenging rate.

Table 4. The scavenging effect of APS on $\mathrm{H}_{2} \mathrm{O}_{2}(n=6)$. Data were expressed as means \pm S.D. and statistical differences between groups were analyzed by one-way analysis of variance (ANOVA).

\begin{tabular}{cccc}
\hline Group & Concentration $(\mathbf{m g} / \mathbf{L})$ & $\mathbf{V}\left(\mathrm{Na}_{2} \mathbf{S}_{2} \mathbf{O}_{3} \mathbf{m L}\right)$ & $\mathbf{S R} \%$ \\
\hline Control & - & $1.638 \pm 0.057$ & \\
APS & 4 & $1.544 \pm 0.051^{\mathrm{a}}$ & 5.74 \\
& 8 & $1.364 \pm 0.042^{\mathrm{b}}$ & 16.73 \\
& 16 & $1.116 \pm 0.029^{\mathrm{b}}$ & 31.87 \\
& 32 & $0.860 \pm 0.032^{\mathrm{b}}$ & 47.50 \\
& 64 & $0.688 \pm 0.026^{\mathrm{b}}$ & 58.00 \\
& 128 & $0.536 \pm 0.023^{\mathrm{b}}$ & 67.28 \\
\hline
\end{tabular}

\subsection{Improvement in the Activities of CAT, SOD, GPx and Anti-hydroxyl Radical}

Vitamin E is the major lipid-soluble chain-breaking antioxidant in mammals and plays an important role in normal development and physiology [34]. Studies have shown that tocopherols scavenge and quench various reactive oxygen species and lipid oxidation by-products, which would otherwise propagate LPO chain reactions in membranes [35]. The standard antioxidant compound $\alpha$-tocopherol, the most biologically active form of vitamin $\mathrm{E}$ [36], is a primary antioxidant functioning by terminating free-radical chain reactions by donating hydrogen or electrons to free radicals and converting them to more stable products [37]. $\alpha$-Tocopherol has a potency to induce the increase in free radical-scavenging enzyme activities [38,39]. The lipophilic radical scavenger $\alpha$-tocopherol, present in mitochondrial membranes, also has a role in interfering with the propagation of free radical-mediated chain reactions, thereby protecting membrane lipids from peroxidation [40]. CAT, SOD, GPx and anti-hydroxyl radical activities in liver homogenate of model group mice were decreased significantly versus normal group, the oral supplementation of vitamin $\mathrm{E}$ was found to increase the activities of CAT, SOD, GPx and anti-hydroxyl radical in this study. The ability of APS2 (200 mg/kg/d) on increasing CAT, SOD, GPx and anti-hydroxyl radical activities is vitamin E 
(100 mg/kg/d) comparable. Comparisons with model mice, the activities of CAT, SOD, GPx and anti-hydroxyl radical in APS3 group $(300 \mathrm{mg} / \mathrm{kg} / \mathrm{d})$ were significantly increased, almost reaching normal levels $(P>0.05)$. APS increased CAT, SOD, GPx and anti-hydroxyl radical activities in a dose-dependent manner (Table 5). These results demonstrated that APS could enhance activities of the antioxidases and the ability of scavenging $\bullet \mathrm{OH}$ in vivo.

Table 5. Effects of APS on the CAT, SOD, GPx and anti-hydroxyl radical activities in mice liver in vivo $(\mathrm{n}=10)$. Data were expressed as means \pm S.D. and statistical differences between groups were analyzed by one-way analysis of variance (ANOVA).

\begin{tabular}{|c|c|c|c|c|c|}
\hline Group & $\begin{array}{c}\text { Dose } \\
(\mathrm{mg} / \mathrm{kg} / \mathrm{d})\end{array}$ & $\begin{array}{c}\text { CAT } \\
\text { (U/mg protein) }\end{array}$ & $\begin{array}{c}\text { SOD } \\
\text { (U/mg protein) }\end{array}$ & $\begin{array}{c}\text { GPx } \\
\text { (U/mg protein) }\end{array}$ & $\begin{array}{c}\text { Anti-•OH } \\
\text { (U/mg protein) }\end{array}$ \\
\hline Normal & - & $14.3 \pm 3.1^{\mathrm{b}}$ & $268 \pm 45^{b}$ & $58.1 \pm 7.8^{\mathrm{b}}$ & $93.7 \pm 15.2^{b}$ \\
\hline Model & - & $8.5 \pm 3.0$ & $203 \pm 32$ & $41.3 \pm 9.3$ & $62.6 \pm 14.1$ \\
\hline Vit $\mathbf{E}$ & 100 & $12.6 \pm 2.5^{b}$ & $266 \pm 28^{b}$ & $51.7 \pm 6.8^{\mathrm{a}}$ & $88.3 \pm 10.3^{b}$ \\
\hline ASP 1 & 100 & $9.2 \pm 2.4$ & $227 \pm 36$ & $45.3 \pm 7.7$ & $68.1 \pm 8.6$ \\
\hline ASP 2 & 200 & $11.4 \pm 2.6^{\mathrm{a}}$ & $243 \pm 29^{b}$ & $53.5 \pm 6.6^{b}$ & $75.9 \pm 10.8^{\mathrm{a}}$ \\
\hline ASP 3 & 300 & $14.1 \pm 3.3^{b}$ & $271 \pm 33^{b}$ & $57.3 \pm 7.2^{b}$ & $90.5 \pm 13.5^{b}$ \\
\hline
\end{tabular}

Aging is a complex phenomenon, a sum total of changes that occur in a living organism with the passage of time and lead to decreasing ability to survive stress, increasing functional impairment and growing probability of death [41]. ROS are considered to be important causative factors in the aging process [42]. The processes that delay and/or reverse visible signs of aging are termed as anti-aging. Mitochondria are constantly exposed to the danger of ROS-induced oxidative injury. LPO is known to damage the mitochondrial membrane [43]. Approximately $1 \%-5 \%$ of the oxygen consumed by mitochondria in human cells is converted to ROS, including $\mathrm{O}_{2}{ }^{--}, \mathrm{H}_{2} \mathrm{O}_{2}$, and $\bullet \mathrm{OH}$ [44]. It has been shown that the amount of lipid peroxides in mitochondria increases with age [45]. Mitochondrial ROS production and oxidative damage in tissue cells are increased during aging. Cellular antioxidant systems have been traditionally divided into two categories: enzymatic and nonenzymatic. Primary antioxidant enzymes include SOD, GPx and CAT. Non-enzymatic antioxidants, like vitamin E ( $\alpha$-tocopherol) directly scavenge superoxide and $\bullet \mathrm{OH}$, as well as singlet oxygen [46]. GPx, which is probably the best studied mitochondrial antioxidant enzyme, plays an important role in the decomposition of $\mathrm{H}_{2} \mathrm{O}_{2}$ produced in mitochondria. GPx catalyzes $\mathrm{H}_{2} \mathrm{O}_{2}$ and $\mathrm{ROOH}$ reduction by GSH $\left[\mathrm{H}_{2} \mathrm{O}_{2}(\mathrm{ROOH})+2 \mathrm{GSH}=>\mathrm{GSSG}+2 \mathrm{H}_{2} \mathrm{O}\left(\mathrm{ROH}+\mathrm{H}_{2} \mathrm{O}\right)\right]$ and is the unique enzyme that uses $\mathrm{H}_{2} \mathrm{O}_{2}$ in the mitochondria of most mammalian organs [47]. In fact, GPx activity seems to exceed that of any competing $\mathrm{H}_{2} \mathrm{O}_{2}$ scavenger in mitochondria. Despite mostly present in the peroxisomes, CAT might also play a role in the decomposition of mitochondrial $\mathrm{H}_{2} \mathrm{O}_{2}$ to $\mathrm{H}_{2} \mathrm{O}$ [48]. The recent work by Schriner et al. clearly demonstrates that mitochondrially targeted CAT decreases free radicals (mainly $\mathrm{H}_{2} \mathrm{O}_{2}$ ), leads to reduced mitochondrial oxidative damage, and increases the lifespan of CAT transgenic mice [49], suggesting that overexpressed CAT in mitochondria decreases ROS and boosts the functioning of mitochondria. 


\section{Materials and Methods}

\subsection{Plant Materials and Animals}

Astragali Radix was collected in the primitive forest of Daxing'anling region in Heilongjiang Province of China, which was authenticated by professor Haixue Kuang as the roots of Astragalus membranaceus (Fisch.) Bunge var. mongholicus (Bunge) Hsiao (AM), and its voucher specimen was deposited in the Herbarium of Chinese Herbal Medicines, College of Pharmacy, Heilongjiang University of Traditional Chinese Medicine.

Male BALB/c mice (Certificate No. SCXKGGD2004-0017), weighing $22 \pm 2.0 \mathrm{~g}$, were purchased from the Experimental Animal Center, Dalian Medical University. All mice were cared according to the Guiding Principles in the Care and Use of Animals. The experiment was approved by Animal Care Committee of Dalian Medical University (China) in accordance with the Chinese Council on Animal Care Guidelines. Rodent laboratory chow and tap water were available ad libitum during the period.

Animal groups of in vivo experiments: Sixty mice were randomly assigned into 6 groups (Normal, Model, Vit E and APS1, 2, 3. $\mathrm{n}=10$ for each group). APS $(100,200,300 \mathrm{mg} / \mathrm{kg} / \mathrm{d})$ was administered by oral gavage to mice in APS1, 2, 3 group respectively. Vitamin E (100 mg/kg/d) was administered to mice in Vit E group and an equivalent volume of normal saline to mice in Normal and Model group. All the mice except the Normal group were administered D-galactose (100 mg/kg/d) subcutaneously and the Normal group mouse an equivalent volume of normal saline. Each index was determined 7 weeks later.

\subsection{Chemicals}

Coomassie brilliant blue G-250 (CBBG-250) and N-methylphenazonium methyl sulfate (PMS) were purchased from Fluka (Bushs SG, Switzerland). Bovine serum albumin (BSA), 4-nitrobluetetrazolium chloride (NBT) and NADH were from Boehringer Mannheim Corp. (Indianapolis, IN, USA). 2-Thiobarbituric acid (TBA) and 1, 1, 3, 3-tetraethoxypropane (TEP) were from Sigma Chemical (St Louis, MO, USA). HEPES was from Merck (Darmstadt, Germany). Tris was from Gibco BRL (Grand Island, NY, USA). 3-( $N$-Morpholino) propanesulfonic acid (MOPS) was from Solarbio (Beijing, China). Ruthenium red (RR) was from Alfa Aesar (Heysham, Lancashire, United Kingdom). Commercial CAT, SOD, GPx and anti-hydroxyl radical monitoring kits were from Nanjing Jiancheng Bioengineering Institute (Nanjing, China). The name of commercial kits used for determination of CAT, SOD, GPx and ant-hydroxyl radical activities are Reagent of Detection for Catalase, Surperoxide Dismutase, Glutathione Peroxidase and Reactive Oxygen Species respectively. Vitamin E (Vit E) was from Shanghai Xinyi Pharmaceutical Factory (Shanghai, China). D-galactose was from Shanghai Second Reagent Factory (Shanghai, China). All other chemicals and solvents used in the study were of analytical grade made in China.

\subsection{Preparation of the Astragalus Polysaccharides}

The collected AM was washed, dried, pulverized, then immersed in distilled water (the ratio of AM and distilled water was 1:15) for $24 \mathrm{~h}$ and extracted thrice with distilled water for $1 \mathrm{~h}$ each in a boiling 
water bath. The filtrate was collected after filtration with gauze, mixed and condensed to $1 \mathrm{~g}$ crude $\mathrm{drug} / \mathrm{mL}$ by rotary evaporation. Sevage reagents (ratio of chloroform and n-butanol was 4:1) were used to remove all protein constituents. The resultant liquor was precipitated with 3 times volume of $95 \%$ ethanol. Precipitation of polysaccharides proceeded at $4{ }^{\circ} \mathrm{C}$ for $24 \mathrm{~h}$ and the precipitate which was collected by centrifugation at $5000 \times \mathrm{g}$ for $10 \mathrm{~min}$ was dissolved in distilled water, ethanol was added to final concentration of $25 \%$ to settle. The precipitate was discarded and the supernatant was added with $95 \%$ ethanol to final concentration of $75 \%$ and stood at $4{ }^{\circ} \mathrm{C}$ for $24 \mathrm{~h}$ after centrifugation at 5000 $\times \mathrm{g}$ for $10 \mathrm{~min}$. The resultant precipitate was washed with $95 \%$ ethanol and water-free ethanol respectively after suction and lyophilized in vасио. The polysaccharides content $(91.6 \%)$ in extracts was determined using the phenol-sulfuric acid method [50].

\subsection{Isolation of Mitochondria}

Mitochondria were isolated by differential centrifugation using a modified protocol of Fink et al. [51]. Mice were dislocated, the livers and brains were excised immediately, placed in precooled normal saline to wash the blood on the surface, then they were placed in an ice-cold isolation medium (containing 0.25 M sucrose, $0.5 \mathrm{mM}$ EDTA and $3 \mathrm{mM}$ HEPES, pH 7.4) and were homogenized with a motor-driven Teflon pestle in wet ice. Following homogenization, samples were centrifuged at $1000 \times \mathrm{g}$ for $10 \mathrm{~min}$. A Beckman JA-25.50 rotor and Beckman Coulter Avanti J-E centrifuge were used in this and all other centrifugation steps at $4{ }^{\circ} \mathrm{C}$. Supernatants were removed and centrifuged at $10,000 \times \mathrm{g}$ for $10 \mathrm{~min}$. The pellets were washed twice in the isolation medium, and respun at $10,000 \times \mathrm{g}$ for $10 \mathrm{~min}$ each. After the final wash, mitochondria were resuspended in the same medium and stored in ice until use. Protein determinations were carried out by Bradford method using BSA as a standard [52].

\subsection{Measurement of Thiobarbituric Acid Reactive Substances}

The contents of TBARS in the liver and brain mitochondria were measured according to the method of Chen et al. with slight modification [53]. Mitochondrial protein $(0.5 \mathrm{mg})$ in each tube was incubating with graded concentrations $(2-32 \mathrm{mg} / \mathrm{L}$ ) of APS (the normal and model group were excluded) at $37{ }^{\circ} \mathrm{C}$ for $5 \mathrm{~min}$, then $\mathrm{FeSO}_{4}(0.25 \mathrm{mM}$, the normal group wasn't added $)$ and vitamin $\mathrm{C}$ $(0.6 \mathrm{mM})$ were added. PBS (0.1 M, pH 7.4) was added to $2 \mathrm{~mL}$ (Mitochondria and APS were not added to the blank reference tube). After incubating the mixture in a vibratory incubator at $37{ }^{\circ} \mathrm{C}$ for $30 \mathrm{~min}, 0.5 \mathrm{~mL}$ of $20 \%$ trichloroacetic acid was added to end the reaction. Two milliliters supernatant was transferred to another tube after centrifugation $(9000 \times \mathrm{g})$ for $10 \mathrm{~min}$, to which $1.0 \mathrm{~mL}$ of $0.67 \%$ TBA was added and then heated in a boiling water bath for $10 \mathrm{~min}$. After cooling with tap water, the absorbance at $532 \mathrm{~nm}$ was determined on an UV-Visible spectrophotometer and the blank reference tube was used to zero. TBARS contents $(C)$ was measured by linear regression analysis of an aliquot using TEP as an external standard. The TBARS inhibition rate (IR\%) was calculated according to the following equation:

$$
\text { IR } \%=\left[\left(C_{\text {model }}-C_{\mathrm{APS}}\right) /\left(C_{\text {model }}-C_{\text {nomal }}\right)\right] \times 100
$$




\subsection{Evaluation of Mitochondrial Permeability Transition}

Liver mitochondria were isolated and resuspended $(0.25 \mathrm{mg}$ of protein $/ \mathrm{mL})$ in an incubation medium (250 mM sucrose, $1 \mathrm{mM} \mathrm{P} \mathrm{P}_{\mathrm{i}}$-Tris, $10 \mathrm{mM}$ Tris-MOPS, $5 \mathrm{mM}$ glutamate-Tris, $2.5 \mathrm{mM}$ malate-Tris, $\left.\mathrm{pH} 7.4,25^{\circ} \mathrm{C}\right) .150 \mu \mathrm{M} \mathrm{Ca}^{2+}$ was added followed by APS or ruthenium red $(0.3$ or $0.5 \mu \mathrm{M}$ ) (the model group was excluded). Experiments were started by the addition of $0.5 \mathrm{mg}$ of mitochondria. The final volume was $2 \mathrm{~mL}$. Mitochondrial PT was monitored as the absorbance (A) decrease of the mitochondrial suspension at $540 \mathrm{~nm}$ at $0,2,5,10,15$, and $30 \mathrm{~min}[54,55]$.

\subsection{Assay of Superoxide Anion Scavenging Activity}

Superoxide anion was generated in NADH/PMS system and was measured by the nitrobluetetrazolium (NBT) reduction method that superoxide radicals reduce NBT into a

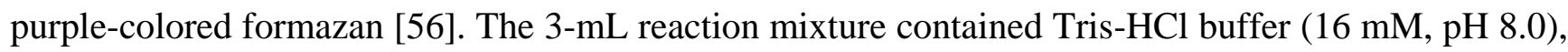
NADH $(73 \mu \mathrm{M})$, NBT $(50 \mu \mathrm{M})$ and various concentrations $(4-64 \mathrm{mg} / \mathrm{L})$ of APS (not added to the control group). After adding PMS solution (15 $\mu \mathrm{M}$, the blank was excluded) to the mixture, the reaction mixture was incubated at $25{ }^{\circ} \mathrm{C}$ for $2 \mathrm{~min}$, and the absorbance (A) at $560 \mathrm{~nm}$ was measured against blank samples. Decreased absorbance of the reaction mixture indicated increased superoxide anion scavenging activity. Vitamin $\mathrm{C}$ was used as positive control. The superoxide anion scavenging rate $(\mathrm{SR} \%)$ was calculated according to the following equation:

$$
\mathrm{SR} \%=\left[\left(A_{\text {control }}-A_{\text {APS or Vitamin C }}\right) / A_{\text {control }}\right] \times 100
$$

\subsection{Hydrogen Peroxide Scavenging Activity Assay}

Hydrogen peroxide scavenging activity of APS and standards was assayed by the method of Zhao [31]. Aliquot of $\mathrm{H}_{2} \mathrm{O}_{2}(1.0 \mathrm{~mL}, 0.1 \mathrm{mM})$ and $1.0 \mathrm{~mL}$ of various concentrations of APS were mixed, followed by $100 \mu \mathrm{L} \mathrm{3 \%}$ ammonium molybdate, $10 \mathrm{~mL} \mathrm{H}_{2} \mathrm{SO}_{4}(2 \mathrm{M})$ and $7.0 \mathrm{~mL} \mathrm{KI}(1.8 \mathrm{M})$. The mixed solution was titrated with $5 \mathrm{mM} \mathrm{Na}_{2} \mathrm{~S}_{2} \mathrm{O}_{3}$ until the yellow color disappeared. The percentage scavenging effect was calculated as Scavenging rate $(\mathrm{SR} \%)=\left[\left(V_{0}-V_{1}\right) / V_{0}\right] \times 100$, where $V_{0}$ was volume of $\mathrm{Na}_{2} \mathrm{~S}_{2} \mathrm{O}_{3}$ solution used to titrate the control sample in the presence of hydrogen peroxide (without APS), $V_{1}$ was the volume of $\mathrm{Na}_{2} \mathrm{~S}_{2} \mathrm{O}_{3}$ solution used in the presence of APS.

\subsection{Hydroxyl Radicals Scavenging Activity Assay}

The Fenton reaction system of a final volume of $2 \mathrm{~mL}$ contained $0.75 \mathrm{mM} \mathrm{FeSO}, 0.75 \mathrm{mM}$ 1,10-phenanthroline, $0.8 \mathrm{mM} \mathrm{H} \mathrm{H}_{2}, 150 \mathrm{mM}$ PBS buffer and APS (4-64 mg/L) or BHT $(0.30-2.4 \mathrm{mg} / \mathrm{L})$ at different concentrations. BHT was used as positive control. Reaction was started by adding $\mathrm{H}_{2} \mathrm{O}_{2}$ and the tubes were incubated for $60 \mathrm{~min}$ in a water bath at $37{ }^{\circ} \mathrm{C}$ [57]. The absorbance of the $\mathrm{Fe}^{2+}$-phenanthroline complex was measured at $536 \mathrm{~nm}$. $\cdot \mathrm{OH}$ scavenging by APS was calculated according to the following equation: SR $\%=\left[\left(A_{1}-A_{0}\right) /\left(A_{2}-A_{0}\right)\right] \times 100\left[A_{0}\right.$ : Control; $A_{1}$ : APS or BHT; $A_{2}$ : Blank without drug and $\mathrm{H}_{2} \mathrm{O}_{2}$ ]. 


\subsection{Determination on the Activities of CAT, SOD, GPx and Anti-hydroxyl Radical}

Mice were killed via dislocation, and livers were rapidly removed, weighed and made into $1 \%$ homogenates with normal saline at $0{ }^{\circ} \mathrm{C}$. Two milliliters of homogenate was centrifuged at $2000 \times \mathrm{g}$ for $5 \mathrm{~min}, 100 \mu \mathrm{L}$ supernatant was added to $900 \mu \mathrm{L}$ normal saline and mixed, $10 \mu \mathrm{L}$ of which was used for determination of CAT, SOD, GPx and anti-hydroxyl radical activities by using commercial monitoring kits respectively, following the manufacturer's protocol.

\subsection{Statistical Analysis}

Data were expressed as means \pm S.D. of three replicates and the tables represent the average of replicate experiments. Statistical differences between groups were analyzed by one-way analysis of variance (ANOVA) followed by least significant difference (LSD) post hoc multiple comparisons test using the statistical software package SPSS 16.0 for Windows (SPSS Inc., Chicago, IL, USA). Results were considered statistically significant at the probability $(P)$ values $<0.05$ level.

\section{Conclusions}

The present study shows that APS inhibit mitochondrial injury and swelling and also had significant ROS scavenging effect. APS clearly inhibit the generation of TBARS in mitochondria, which indicates that it can significantly protect the body from LPO. The inhibition of LPO and mitochondrial swelling suggests that APS may inhibit the generation of ROS in mitochondria. APS can interfere with the oxidation process by reacting with free radicals, and also by acting as ROS scavengers. From the standpoint of health and longevity, our results indicate that APS may protect mitochondria from oxidative damage. Moreover, APS notably increase the activities of the antioxidases. In conclusion, APS would have a beneficial effect on protecting mitochondria while maintaining efficient cellular metabolism.

The electron transport chain (ETC) in the mitochondrial inner membrane is actively involved in adenosine triphosphate (ATP) synthesis in combination with respiration, which consumes approximately $90 \%$ of the oxygen uptake of the tissue cells. A fraction of the oxygen is incompletely reduced to generate ROS and organic free radicals, which are usually disposed of by the coordinated function of antioxidant enzymes. If ROS escape, they may facilitate LPO and cause oxidative damage, at least transiently, to the inner membrane. Iron-induced LPO alter mitochondrial respiration and oxidative phosphorylation (OXPHOS). The impaired ETC works less efficiently in ATP synthesis and generates more ROS, which will cause further oxidative damage to various biomolecules in mitochondria. In the aging process, oxidative damage ultimately leads to a progressive decline in bioenergetic function and enhanced mitochondrial oxidative stress. The energy depletion and enhanced oxidative stress can lead to the aging process. APS can protect mitochondria by scavenging ROS, inhibiting LPO and mitochondrial swelling, and increasing the activities of antioxidant enzymes. Therefore, perhaps APS ameliorate mitochondrial dysfunction ultimately by improving energy metabolism; this may be the hypothetical mechanism of APS on mitochondrial protection and antiaging activity. 


\section{Acknowledgments}

This work was supported by the Fundamental Research Funds for the Central Universities in China (grant number: C10030105); the Post-doctoral Research Station of Daxing'anling Beiqishen Green Industry Group, Doctoral Research Center of Heilongjiang University of Traditional Chinese Medicine (No.LRB10-316); and the Talents Project of Dalian Nationalities University (No.20116126).

\section{References}

1. Vina, J.; Sastre, J.; Pallardo, F.; Borras, C. Mitochondrial theory of aging: Importance to explain why females live longer than males. Antioxid. Redox Signal 2003, 5, 549-556.

2. Harman, D. Free radical theory of aging: An update: Increasing the functional life span. Ann. N. Y. Acad. Sci. 2006, 1067, 10-21.

3. Manczak, M.; Jung, Y.; Park, B.S.; Partovi, D.; Reddy, P.H. Time-course of mitochondrial gene expressions in mice brains: Implications for mitochondrial dysfunction, oxidative damage, cytochrome c release in aging. J. Neurochem. 2005, 92, 494-504.

4. Navarro, A.; Boveris, A. The mitochondrial energy transduction system and the aging process. Am. J. Physiol. Cell Physiol. 2007, 292, 670-686.

5. Kwong, J.Q.; Flint Beal, M.; Manfred, G. The role of mitochondria in inherited neurodegenerative diseases. J. Neurochem. 2006, 97, 1659-1675.

6. Gustafsson, A.B.; Gottlieb, R.A. Heart mitochondria: Gates of life and death. Cardiovasc. Res. 2008, 77, 334-343.

7. Turrens, J.F. Mitochondrial formation of reactive oxygen species. J. Physiol. 2003, 52, 335-344.

8. Reddy, P.H. Amyloid precursor protein-mediated free radicals and oxidative damage: Implications for the development and progression of Alzheimer's disease. J. Neurochem. 2006, 96, 1-13.

9. Droge, W. Free radicals in the physiological control of cell function. Physiol. Rev. 2002, 82, 47-95.

10. Zheng, X.Y. Pharmacopoeia of the People's Republic of China, 8th ed.; Chemical Industry Press: Beijing, China, 2005; Volume 1, pp. 212-213.

11. Wang, P.; Zhang, Z.; Ma, X.; Huang, Y.; Liu, X.; Tu, P.; Tong, T. HDTIC-1 and HDTIC-2, two compounds extracted from Astragali Radix, delay replicative senescence of human diploid fibroblasts. Mech. Ageing Dev. 2003, 124, 1025-1034.

12. Cheng, X.D.; Hou, C.H.; Zhang, X.J.; Xie, H.Y.; Zhou, W.Y.; Yang, L.; Zhang, S.B.; Qian, R.L. Effects of Huangqi (Hex) on inducing cell differentiation and cell death in K562 and HEL cells. Acta Biochim. Biophys. Sin. 2004, 36, 211-217.

13. Luo, Z.; Zhong, L.; Han, X.; Wang, H.; Zhong, J.; Xuan, Z. Astragalus membranaceus prevents daunorubicin-induced apoptosis of cultured neonatal cardiomyocytes: Role of free radical effect of Astragalus membranaceus on daunorubicin cardiotoxicity. Phytother. Res. 2009, 23, 761-767.

14. Hong, C.Y.; Lo, Y.C.; Tan, F.C.; Wei, Y.H.; Chen, C.F. Astragalus membranaceus and Polygonum multijlorum protect rat heart mitochondria against lipid peroxidation. Am. J. Chin. Med. 1994, 22, 63-70. 
15. Zhang, L.J.; Liu, H.K.; Hsiao, P.C.; Kuo, L.M.; Lee, I.J.; Wu, T.S.; Chiou, W.F.; Kuo, Y.H. New isoflavonoid glycosides and related constituents from astragali radix (Astragalus membranaceus ) and their inhibitory activity on nitric oxide production. J. Agric. Food Chem. 2011, 59, 1131-1137.

16. Li, S.; Zhang, Y. Characterization and renal protective effect of a polysaccharide from Astragalus membranaceus. Carbohydr. Polym. 2009, 78, 343-348.

17. Shao, B.M.; Xu, W.; Dai, H.; Tu, P.; Li, Z.; Gao, X.M. A study on the immune receptors for polysaccharides from the roots of Astragalus membranaceus, a Chinese medicinal herb. Biochem. Biophys. Res. Commun. 2004, 320, 1103-1111.

18. Yin, X.; Chen, L.; Liu, Y.; Yang, J.; Ma, C.; Yao, Z.; Yang, L.; Wei, L.; Li, M. Enhancement of the innate immune response of bladder epithelial cells by Astragalus polysaccharides through upregulation of TLR4 expression. Biochem. Biophys. Res. Commun. 2010, 397, 232-238.

19. Mao, X.Q.; Yu, F.; Wang, N.; Wu, Y.; Zou, F.; Wu, K.; Liu, M.; Ouyang, J.P. Hypoglycemic effect of polysaccharide enriched extract of Astragalus membranaceus in diet induced insulin resistant C57BL/6J mice and its potential mechanism. Phytomedicine 2009, 16, 416-425.

20. Chen, R.; Shao H.; Lin, S.; Zhang, J.J.; Xu, K.Q. Treatment with Astragalus membranaceus produces antioxidative effects and attenuates intestinal mucosa injury induced by intestinal ischemia-reperfusion in rats. Am. J. Chin. Med. 2011, 39, 879-887.

21. Ko, J.K.S.; Chik, C.W.S. The protective action of radix Astragalus membranaceus against hapten-induced colitis through modulation of cytokines. Cytokine 2009, 47, 85-90.

22. Cho, W.C.; Leung, K.N. In vitro and in vivo anti-tumor effects of Astragalus membranaceus. Cancer Lett. 2007, 252, 43-54.

23. Paradies, G.; Ruggiero, F.M.; Petrosillo, G.; Quagliariello, E. Age-dependent decline in the cytochrome c oxidase activity in rat heart mitochondria: Role of cardiolipin. FEBS Lett. 1997, 406, 136-138.

24. Armstrong, J.S. The role of the mitochondrial permeability transition in cell death. Mitochondrion 2006, 6, 225-234.

25. Spiteller, G. Lipid peroxidation in aging and age dependent diseases. Exp. Gerontol. 2001, 36, 1425-1457.

26. Valls, V.; Peiro, C.; Munizc, P.; Saez, G.T. Age-related changes in antioxidant status and oxidative damage to lipids and DNA in mitochondria of rat liver. Process Biochem. 2005, 40, 903-908.

27. Faist, V.; Koenig, J; Hoeger, H.; Elmadfa, I. Mitochondrial oxygen consumption, lipid peroxidation and antioxidant enzyme systems in skeletal muscle of senile dystrophic mice. Pflugers Arch. 1998, 437, 168-171.

28. Halestrap, A.P; Clarke, S.J; Javadov, S.A. Mitochondrial permeability transition pore opening during myocardial reperfusion-A target for cardioprotection. Cardiovasc. Res. 2004, 61, 372-385.

29. Kroemer, G.; Dallaporta, B.; Resche-Rigon, M. The mitochondrial death/life regulator in apoptosis and necrosis. Annu. Rev. Physiol. 1998, 60, 619-642.

30. Petronilli, V.; Cola, C.; Massari, S.; Colonna, R.; Bernardi, P. Physiological effectors modify voltage sensing by the cyclosporin A-sensitive permeability transition pore of mitochondria. J. Biol. Chem. 1993, 268, 21939-21945. 
31. Zhao, G.R.; Xiang, Z.J.; Ye, T.X.; Yuan, Y.J.; Guo, Z.X. Antioxidant activities of Salvia miltiorrhiza and Panax notoginseng. Food Chem. 2006, 99, 767-774.

32. Leeuwenburgh, C.; Heinecke, J.W. Oxidative stress and antioxidants in exercise. Curr. Med. Chem. 2001, 8, 829-838.

33. Brookes, P.S. Mitochondrial $\mathrm{H}(+)$ leak and ROS generation: An odd couple. Free Radic. Biol. Med. 2005, 38, 12-13.

34. Cuddihy, S.L.; Ali, S.S.; Musiek, E.S.; Lucero J.; Kopp. S.J.; Morrow, J.D.; Dugan, L.L. Prolonged $\alpha$-tocopherol deficiency decreases oxidative stress and unmasks $\alpha$-tocopherol-dependent regulation of mitochondrial function in the brain. J. Biol. Chem. 2008, 2839, 6915-6924.

35. Kamal-Eldin, A.; Appelqvist, L. The chemistry and antioxidant properties of tocopherols and tocotrienols. Lipids 1996, 31, 671-701.

36. Yusuf, M.A.; Sarin, N.B. Antioxidant value addition in human diets: Genetic transformation of Brassica juncea with gamma-TMT gene for increased alpha-tocopherol content. Transgenic Res. 2007, 16, 109-113.

37. Aardt, M.V.; Duncan, S.E.; Marcy, J.E.; Long, T.E.; O’Keefe, S.F.; Nielsen-Sims, S.R. Effect of antioxidant ( $\alpha$-tocopherol and ascorbic acid) fortification on light-induced flavor of milk. J. Dairy Sci. 2005, 88, 872-880.

38. Musalmah, M.; Nizrana, M.Y.; Fairuz, A.H.; Noor Aini A.H; Azian, A.L.; Gapor, M.T.; Wan Ngah, W.Z. Comparative effects of palm vitamin $\mathrm{E}$ and alpha-tocopherol on healing and wound tissue antioxidant enzyme levels in diabetic rats. Lipids 2005, 40, 575-580.

39. Chitra, S.; Shyamala Devi, C.S. Effect of alpha-tocopherol on pro-oxidant and antioxidant enzyme status in radiation-treated oral squamous cell carcinoma. Indian J. Med. Sci. 2008, 62, 141-148.

40. Andreyev, A.Y.; Kushnareva, Y.E.; Starkov, A.A. Mitochondrial metabolism of reactive oxygen species. Biochemistry 2005, 70, 200-214.

41. Datta, H.S.; Mitra, S.K.; Paramesh, R.; Patwardhan, B. Theories and management of aging: Modern and Ayurveda perspectives. Evid. Based Complement. Altern. Med. 2011, 2011, 528527:1-528527:6.

42. Datta, H.S.; Mitra, S.K.; Patwardhan, B. Wound healing activity of topical application forms based on Ayurveda. Evid. Based Complement. Altern. Med. 2011, 2011, 134378:1-134378:10.

43. Ohnishi, S.T.; Ohnishi, T.; Nishino, K. Ki-Energy (life-energy) protects isolated rat liver mitochondria from oxidative injury. Evid. Based Complement. Altern. Med. 2006, 3, 475-482.

44. Beckman, K.B.; Ames, B.N. The free radical theory of aging matures. Physiol. Rev. 1998, 78, 547-581.

45. Hruszkewycz, A.M. Lipid peroxidation and mtDNA degeneration. A hypothesis. Mutat. Res. 1992, 275, 243-248.

46. Yu, B.P. Cellular defenses against damage from reactive oxygen species. Physiol. Rev. 1994, 74, 139-162.

47. Chance, B.; Sies, H.; Boveris, A. Hydroperoxide metabolism in mammalian organs. Physiol. Rev. 1979, 59, 527-605.

48. Cadenas, E.; Davies, K.J. Mitochondrial free radical generation, oxidative stress, and aging. Free Radic. Biol. Med. 2000, 29, 222-230. 
49. Schriner, S.E.; Linford, N.J.; Martin, G.M.; Treuting, P.; Ogburn, C.E.; Emond, M.; Coskun, P.E.; Ladiges, W.; Wolf, N.; van Remmen, H.; et al. Extension of murine life span by overexpression of catalase targeted to mitochondria. Science 2005, 308, 909-911.

50. Dubois, M.; Gilles, K.A.; Hamilton, J.K.; Rebers, P.A.; Smith, F. Colorimetric method for determination of sugars and related substances. Anal. Chem. 1956, 28, 350-356.

51. Fink, B.D.; Reszka, K.J.; Herlein, J.A.; Mathahs, M.M.; Sivitz, W.I. Respiratory uncoupling by UCP1 and UCP2 and superoxide generation in endothelial cell mitochondria. Am. J. Physiol. Endocrinol. Metab. 2005, 288, 71-79.

52. Bradford, M.M. A rapid and sensitive method for the quantation of microgram quantities of protein utilizing the principle of protein-dye binding. Anal. Biochem. 1976, 72, 248-254.

53. Chen, G.T.; Zhao, L.; Zhao, L.Y.; Cong, T.; Bao, S.F. In vitro study on antioxidant activities of peanut protein hydrolysate. J. Sci. Food Agric. 2007, 87, 357-362.

54. Walter, L.; Nogueira, V.; Leverve, X.; Heitz, M.P.; Bernardi, P.; Fontaine, E. Three classes of ubiquinone analogs regulate the mitochondrial permeability transition pore through a common site. J. Biol. Chem. 2000, 275, 29521-29527.

55. He, L.; Poblenz, A.T.; Medrano, C.J.; Fox, D.A. Lead and calcium produce rod photoreceptor cell apoptosis by opening the mitochondrial permeability transition pore. J. Biol. Chem. 2000, 275, 12175-12184.

56. Mandal, S.; Hazra, B.; Sarkar, R.; Biswas, S.; Mandal, N. Assessment of the antioxidant and reactive oxygen species scavenging activity of methanolic extract of Caesalpinia crista leaf. Evid. Based Complement. Alternat. Med. 2011, 2011, 173768:1-173768:11.

57. Lin, Z.; Zhu, D.; Yan, Y.; Yu, B.; Wang, Q.; Shen, P.; Ruan, K. An antioxidant phytotherapy to rescue neuronal oxidative stress. Evid. Based Complement. Alternat. Med. 2011, 2011, 519517: 1-519517:7.

(C) 2012 by the authors; licensee MDPI, Basel, Switzerland. This article is an open access article distributed under the terms and conditions of the Creative Commons Attribution license (http://creativecommons.org/licenses/by/3.0/). 